\title{
CONHECER (E) SABER: RELATOS DE PESSOAS CURADAS DA SÍFILIS
}

\author{
Knowing (and) understanding: reports from people cured of Syphilis \\ Conocer (y) saber: relatos de personas curadas de la Sífilis
}

\author{
Débora de Aro Navega \\ Serviço Nacional de Aprendizagem Comercial - SENAC - Bauru (SP) - Brasil
}

Ana Cláudia Bortolozzi Maia

Universidade Estadual Paulista Júlio de Mesquita Filho - UNESP - Bauru (SP) - Brasil

\section{RESUMO}

Objetivo: Descrever as vivências relatadas por pessoas curadas da sífilis sobre o contágio, o diagnóstico e as informações sobre a infecção. Métodos: Pesquisa descritiva com abordagem qualitativa, na qual participaram oito colaboradores de um Centro de Saúde Especializado em Infecções Sexualmente Transmissíveis/Síndrome da imunodeficiência adquirida (IST/AIDS) em 2015, no município de Bauru, São Paulo, Brasil. Os dados foram coletados através de entrevista semiestruturada, a partir de uma questão inicial para posterior análise de conteúdo. Resultados: Desvelaram-se três categorias temáticas: "A ocorrência do contágio da sífilis", "A busca e as reações emocionais diante do diagnóstico", "As informações sobre a sífilis". A primeira categoria evidenciou que a vulnerabilidade dos colaboradores era permeada por desinformação, confiança no parceiro, comportamentos sexuais de risco e descoberta tardia. A segunda categoria demonstrou que geralmente busca-se o diagnóstico quando há a manifestação de sintomas e, diante dele, há reações emocionais de espanto e culpa a si ou ao parceiro. A terceira categoria deixou claro que eram insuficientes os conhecimentos prévios e as informações recebidas nos atendimentos com profissionais de saúde que os acolheram e orientaram, e que contribuíram para a aceitação do diagnóstico, a decisão e a adesão ao tratamento. Conclusão: O estudo evidenciou que o contágio da doença ocorreu pela desinformação, confiança no parceiro e comportamentos sexuais de risco, havendo manifestação de sintomas e reações emocionais dos pacientes.

Descritores: Autocuidado; Educação em Saúde; Diagnóstico; Prevenção de Doenças; Sífilis.

\section{ABSTRACT}

Objective: To describe the experiences reported by people cured of syphilis on the contagion, diagnosis and information about the infection. Methods: Descriptive research with a qualitative approach, which comprised eight collaborators at a Specialized Health Center in Sexually Transmitted Infections/Acquired Immunodeficiency Syndrome (STI/AIDS) in 2015, in the city of Bauru, São Paulo, Brazil. Data was collected by means of a semi- structured interview, from an initial question followed by content analysis. Results: Three thematic categories were unveiled: "The occurrence of syphilis transmission", "The search and emotional reactions to the diagnosis" and "The information on syphilis". The first category evidenced that the vulnerability of the collaborators was permeated by misinformation, confidence in the partner, risky sexual behaviors and late discovery. The second category demonstrated that the diagnosis is usually sought when symptoms manifest themselves and, when faced with that, there are emotional reactions of astonishment, self-blame or blaming on the partner. The third category made it clear that there was little previous knowledge and that the information received in the visits to the health professionals who embraced and guided them contributed to the acceptance of diagnosis, the decision and adherence to treatment. Conclusion: The study evidenced that the disease transmission occurred because of misinformation, confidence in the partner and risky sexual behaviors, with manifestation of symptoms and emotional reactions of the patients.

Descriptors: Self-care; Health Education; Diagnosis; Disease Prevention; Syphilis. 


\section{RESUMEN}

Objetivo: Describir las vivencias relatadas por personas que han sido curadas de la sifilis respecto el contagio, el diagnóstico y las informaciones de la infección. Métodos: Investigación descriptiva de abordaje cualitativo en la cual han participado ocho colaboradores de un Centro de Salud Especializado en Infecciones de Transmisión Sexual /Síndrome de Inmunodeficiencia Adquirida (ITS/SIDA) en 2015 en el municipio de Bauru, São Paulo, Brasil. Se recogieron los datos a través de entrevista semiestructurada a partir de una pregunta inicial para el análisis de contenido a posteriori. Resultados: Se han desvelado tres categorías temáticas: "La ocurrencia del contagio de la sifilis", "La búsqueda y las reacciones emocionales ante el diagnóstico", "Las informaciones sobre la sifilis". La primera categoría ha evidenciado que la vulnerabilidad de los colaboradores era permeada por la desinformación, la confianza en el compañero, las actitudes sexuales de riesgo y el descubrimiento tardío. La segunda categoría ha demostrado que en general se busca el diagnóstico cuando hay la manifestación de los síntomas y que ante el diagnóstico hay reacciones emocionales de espanto y culpa de uno mismo o de su compañero. La tercera categoría ha dejado claro que los conocimientos previos no eran suficientes y que las informaciones recibidas en las consultas con los profesionales sanitarios que les han acogido y les han orientado han contribuido para la aceptación del diagnóstico, la decisión y la adhesión al tratamiento. Conclusión: El estudio ha evidenciado que el contagio de la enfermedad se dio por la desinformación, la confianza en el compañero y las actitudes sexuales de riesgo con la manifestación de los síntomas y las reacciones emocionales de los pacientes.

Descriptores: Autocuidado; Educación en Salud; Diagnóstico; Prevención de Enfermedades; Sífilis.

\section{INTRODUÇÃO}

A sífilis adquirida é uma infecção sexualmente transmissível (IST) passível de prevenção e cura. Contudo, os dados epidemiológicos demonstram um crescimento na quantidade de casos registrados no Brasil nos últimos anos ${ }^{(1,2)}$, assim também em outros países, como nos Estados Unidos, em Portugal, na França, na Alemanha e no Reino Unido ${ }^{(3,4)}$. No Brasil, entre 2010 e 2016, foram registrados 227.663 casos de sífilis adquirida. Destes, 65.878 foram notificados em 2015, o que significou um aumento de $32,7 \%$ em relação ao ano anterior ${ }^{(1)}$. Esse aumento de casos sugere a necessidade de políticas públicas e ações programáticas na prevenção das IST e no controle da epidemia de sífilis adquirida.

Após a infecção sexual pela bactéria Treponema pallidum, a sífilis manifesta nas fases primária e secundária de sua evolução clínica, respectivamente, uma lesão ulcerativa no local de inoculação da bactéria e lesões de pele, com alta infectividadade (cerca de 60\%). Contudo, por vezes os sintomas são escassos e/ou costumam regredir espontaneamente mesmo na ausência do tratamento, e a infecção progride com períodos de latência assintomáticos. Nessa situação, é comum que a pessoa desconheça ser portadora da infecção e transmita involuntariamente aos seus contatos sexuais, sendo o exame sorológico o meio de obtenção do diagnóstico ${ }^{(5)}$.

A detecção e o tratamento das pessoas com sífilis adquirida é relevante pelo risco de agravamento em longo prazo. Na fase terciária, após dois a quarenta anos do contato sexual, aproximadamente $30 \%$ dos casos não tratados irão manifestar lesões cutâneas, neurológicas, cardíacas e ósseas ${ }^{(2,5)}$.

Além disso, a ocorrência da sífilis, assim como de outras IST, pode provocar impactos psicológicos e sociais na saúde das pessoas acometidas. No caso de gestantes contaminadas, se não estiverem em tratamento, pode haver a transmissão congênita com severos desfechos, como aborto, prematuridade, manifestações congênitas precoces ou tardias e/ou morte do recém-nascido(5), por isso continua a ser um grave problema de saúde pública ${ }^{(6,7)}$.

Os profissionais de saúde devidamente capacitados são considerados como protagonistas no enfrentamento da epidemia de sífilis congênita ${ }^{(6-9)}$. Porém, para uma adequada atuação, é preciso garantir o acolhimento das subjetividades e singularidades dos usuários, estratégias de aconselhamento e programas de educação em saúde ${ }^{(8-10)}$.

Os aspectos cognitivos, subjetivos e culturais podem se constituir em desafios para a prevenção e o diagnóstico da sífilis, assim como para o enfrentamento da condição pelos acometidos. No cuidado centrado na pessoa, pela perspectiva da clínica ampliada ${ }^{(11)}$, deve-se estimular comportamentos de promoção da saúde, de prevenção primária e secundária da sífilis, para que os usuários desenvolvam habilidades de autocuidado visando a autonomia necessária para a preservação e o reestabelecimento de sua saúde.

Mulheres em tratamento para sífilis relataram escassos conhecimentos sobre a doença. Além disso, não receberam orientações pelos profissionais de saúde ou, quando isso ocorreu, relataram dificuldades em assimilar as informações recebidas ${ }^{(12-16)}$. Diante do diagnóstico, relataram sentimentos de tristeza, vergonha, culpa e também preocupação em relação aos sintomas e à cura e à transmissão para o bebê $\hat{e}^{(12-14,16)}$.

Diante dessa problemática, o estudo justifica-se pela necessidade de conhecer as experiências vivenciadas por pessoas com diagnóstico de sífilis que aderiram ao tratamento até a cura da infecção, sendo relevante para a compreensão dos aspectos subjetivos, educacionais e sociais que puderam influenciar suas trajetórias. O estudo apresenta relevância para a promoção da saúde, pois suas ações devem ser voltadas para o desenvolvimento de alternativas que estimulem ou intensifiquem a adoção 
de comportamentos saudáveis, através da atuação dos profissionais de saúde, cujas ações devem ser centradas na promoção, prevenção e assistência.

Diante desse contexto, a pesquisa apresenta como pressuposto: As pessoas acometidas e tratadas por sífilis, tinham algum conhecimento sobre o contágio, o diagnóstico e as informações sobre a infecção? Para responder essa questão, o estudo teve como objetivo descrever as vivências relatadas por pessoas curadas da sífilis sobre o contágio, o diagnóstico e as informações sobre a infecção.

\section{MÉTODOS}

Pesquisa descritiva, com abordagem qualitativa, com enfoque nos aspectos subjetivos e sociais do processo saúde-doença(17), realizada em um Centro de Saúde Especializado em IST/AIDS do município de Bauru, São Paulo, Brasil, local de referência de testagem, aconselhamento e tratamento de infecções.

A seleção da amostra teve início com base nos registros (notificações e fichas de controle de tratamento da sífilis do período 2013 a 2015) desse centro de saúde, buscando possíveis colaboradores entre aqueles que receberam alta médica do tratamento por cura da sífilis. Foram critérios de inclusão preestabelecidos: possuir idade acima de 18 anos; ser legalmente capaz de responder sobre os próprios atos; ter vivenciado o diagnóstico da sífilis e o tratamento com penicilina, seguido de exames de controle até a cura da infecção. E os de exclusão: registro de depressão ou outros transtornos (que impedissem de responder as questões do estudo) e a presença de coinfecção de sífilis e Vírus da Imunodeficiência Humana (HIV).

Assim, 35 pessoas foram selecionadas e contatadas por telefone ou pessoalmente no próprio centro de saúde para o convite de participação no estudo, resultando em oito participantes. A coleta de dados ocorreu entre julho e outubro de 2015, por meio de uma entrevista semiestruturada contendo duas partes. Na primeira fase apuraram-se os dados de identificação, com as variáveis: idade, sexo, grau de escolaridade, renda e estado civil. Na segunda fase, questões norteadoras: "conte para mim como foi para você descobrir que tinha sífilis (o diagnóstico?), sobre o contágio (de quem pegou?), e as informações sobre a infecção?", visando atingir os objetivos propostos.

Os relatos foram transcritos e submetidos à análise de conteúdo, que consistiu na leitura flutuante e exaustiva das entrevistas transcritas, seguida pela identificação das unidades de registro e contexto para a definição das categorias mutuamente exclusivas ${ }^{(18)}$. Com enfoque no objetivo do estudo, a análise desvelou três categorias temáticas: A ocorrência do contágio da sífilis; A busca e as reações emocionais diante do diagnóstico; e As informações sobre a sífilis.

Todos os preceitos éticos em pesquisa com seres humanos foram respeitados na realização do presente estudo, aprovado previamente pelo Comitê de Ética da Universidade Estadual Paulista (UNESP) - Campus de Araraquara (Parecer nº 1.052.260) e pela Comissão de Ética da Secretaria Municipal de Saúde de Bauru, São Paulo, Brasil.

Para fins de identificação dos participantes, nos trechos de seus relatos junto às categorias de análise, utilizou-se a letra "C" (colaborador) seguida por um número correspondente à ordem cronológica da participação no estudo, mais uma indicação quanto ao sexo (M - masculino ou $\mathrm{F}$ - feminino) e idade na ocasião da coleta de dados.

\section{RESULTADOS E DISCUSSÃO}

Serão apresentados a seguir os dados de identificação dos colaboradores para, em seguida, serem apresentadas as categorias que emergiram da análise de conteúdo das entrevistas.

A idade dos participantes variou entre 18 e 51 anos, sendo quatro homens e quatro mulheres, com escolaridade de ensino fundamental incompleto a ensino superior completo, com renda média (individual) mensal de R $\$ 1.500,00$ reais. Quanto ao estado civil, um participante era separado, outro vivia em união estável, e os demais eram solteiros.

\section{A ocorrência do contágio da sífilis}

Esta categoria abrangeu os relatos nos quais os participantes descreveram os fatores associados à ausência de uso do preservativo nas relações sexuais em que suspeitavam ter ocorrido o contágio, tendo como justificativa o relacionamento estável para o não uso do mesmo.

Outra alegação sobre a relação desprotegida era relacionada ao desejo de ser amado, seguido da confiança no parceiro, ao próprio descuido com as práticas sexuais seguras e à aceitação do não uso do preservativo, por vezes atribuindo a si mesmo a "culpa" pelo contágio, como pode ser visto nas falas a seguir:

"Eu achava que isso [sexo] era uma forma de ser amada, entendeu? Inconsciente, e ai (...) acabou acontecendo de ter tido a doença." (C6, F, 30)

“Como eu confiava muito no meu marido, eu não usava camisinha com ele nas nossas relações.” (C5, F, 18)

"Porque era pessoa de todos os tipos, eram garotas, mulheres, entendeu? (...) Então, a gente não se cuida, elas [parceiras] também não se cuidaram." (C3, M, 22) 
"[Acho que peguei] porque eu não tinha parceira fixa. (...) No começo, nós usamos. Nós começamos a usar o preservativo, ela mesmo falou "agora nós já estamos juntos, não vamos usar o preservativo”, aí nós não usamos o preservativo, nós paramos." (C1, M, 51)

"Ela [ex-parceira] falou assim: "Olha, é camisinha, eu não gosto que use, então não precisa, não é, usar?!” A gente, desinformado, descuidado, cai na onda. Creio que ai que foi meu erro.” (C4, $M, 29)$

No momento após o diagnóstico, foi recorrente a suspeita de que o contágio tivesse ocorrido em um relacionamento estável anterior, ou atual, às vezes com menção de infidelidade do parceiro:

“Aí, depois de um dia, ela estava comentando comigo que ela tinha que ir no ginecologista (...)Eu falei "ah, então foi dela que eu peguei." (C1, $M, 51)$

"Ela [ex-parceira] havia já falado: "Olha, é, descobri que eu tive sifilis, tal, tudo mais, faz lá o exame e vê, não é, se você tem também." (C4, M, 29)

"Só que aí vem a história, peguei dos namorados ou peguei do ex-marido? Por quê? Porque o ex-marido me traiu. E se a outra lá não usava preservativo?” (C8, F, 32)

"Olha, pelo que eu saiba, foi do meu parceiro [que peguei], porque eu vivi quatro anos com ele, não é, eu não tive outra pessoa por fora, e sempre sem camisinha com ele, ai eu descobri a traição dele, tudo, não é?” (C7, F, 36)

Os relatos de parte dos participantes acerca do contágio sugerem a inexistência de uma percepção prévia da própria vulnerabilidade às IST nas representações de um sexo com prazer e/ou amor, assim como em uma relação de parceria fixa.

Em outros estudos, além da confiança decorrente da relação de parceria fixa, outros motivos para a não utilização do preservativo foram a dificuldade de negociar o uso com o parceiro, a crença de que seu uso diminui o prazer, a desvalorização pessoal e o uso de álcool e drogas ${ }^{(14,15,16,19)}$.

No estudo em questão, os relatos comprovam que ainda é distante o hábito da atividade sexual predominantemente segura e saudável. Vê-se que a participante $(C 6, F, 30)$ apresenta comprometimento de sua autoestima quando diz que abre mão do preservativo, pois sente "a necessidade de ser amada”. Nessa situação, os profissionais de saúde deveriam ter um olhar abrangente, buscando identificar os problemas individuais do paciente, com adoção de medidas e atividades educativas.

É importante ressaltar que falsas crenças, como associar o risco de contágio pelas IST apenas a um comportamento individual promíscuo ou a parceiros com sinais e sintomas, podem prejudicar a percepção da necessidade de proteção ${ }^{(19,20)}$, a obtenção do diagnóstico e, possivelmente, a aceitação dele.

\section{A busca e as reações emocionais diante do diagnóstico}

Nesta segunda categoria estão os relatos acerca de fatores disparadores para a busca e obtenção do diagnóstico, incluindo relatos sobre uma variedade de reações emocionais ao diagnóstico, alguns dos quais geradores da necessidade de apoio emocional pelos profissionais de saúde.

Em alguns casos, a manifestação do sintoma da fase primária pareceu ter sido um gatilho para a procura do atendimento médico. Essa relação ficou evidente na fala do participante $(\mathrm{C} 4 \mathrm{M})$ que já havia recebido o alerta da ex-parceira, sugerindo que realizasse a testagem para sífilis e, mesmo assim, só buscou realizar o exame após a percepção visível do sintoma.

Também outro (C2M) manifestou a presença da úlcera e tratou a sífilis em um serviço de Pronto Atendimento, porém não foi encaminhado ou orientado sobre o seguimento do tratamento para a cura, voltando a buscar atendimento somente quando manifestou sintoma da fase secundária, o que possivelmente seja um indício de que houve uma falha terapêutica ${ }^{(21)}$, ou uma reinfecção ${ }^{(22,23)}$.

\footnotetext{
"Essa sifilis eu descobri quando surgiu uma ferida." (C1, M, 51)

"Não levei tão a sério [o alerta da ex-parceira], não é, porque eu não via nada em mim, a partir da hora que eu comecei a ver as manchas, aí que eu fiquei preocupado, que ai eu liguei as coisas. O descuido, e ela tinha me avisado." (C4, M, 29)

"Eu comecei a perceber umas manchas vermelhas difusas, bolinhas bem pequenas. E ai eu fui no dermatologista e ela, muito experiente, muito sagaz, pediu o exame VDRL lá, e estava uma titulação até alta, e já era secundária, não é, porque eu já tive. Eu acho que aquela não foi bem curada." (C2, M, 24)
}

Os pesquisados relataram a descoberta da sífilis na realização da testagem, sendo que enquanto uns fizeram o exame para investigar IST diante da percepção de vulnerabilidade (C3M e C8F), outros (C6F e C7F) realizaram o exame por outros motivos: cumprir exigências para um exame admissional ou doar sangue. A infecção assintomática pode dificultar o diagnóstico da sífilis ${ }^{(5)}$ e a aceitação do tratamento ${ }^{(9)}$.

A participante C6F conta que havia realizado a testagem para sífilis no passado, porém não quis consultar o resultado. Havia realizado também outra testagem para IST que não incluiu a sífilis, o que justificou o sentimento de vergonha para falar sobre 
sexualidade com o/a profissional de saúde, sobretudo sendo ele do sexo masculino. Desse modo, ela ficou 10 anos com a doença sem saber, até o diagnóstico aparecer ao realizar uma doação de sangue.

A dificuldade relatada por ela em expor suas experiências sexuais e preocupações a/ao profissional de saúde se constituiu em barreira para a realização da testagem específica para a sífilis, o que talvez possa ocorrer com outras pessoas. Essa questão deve ser considerada na relação entre o/a médico/a ou enfermeiro/a e o/a paciente, no sentido de facilitar uma comunicação que envolva o acolhimento e a confiança, atitudes necessárias para ações educativas efetivas visando a aprendizagem de comportamentos preventivos em relação à sífilis ${ }^{(5,9)}$.

"E nessa, que ela engravidou, eu resolvi fazer um exame, porque eu me preocupei com meu filho, eu me preocupei comigo, com meu filho, e falei: "ah, está na hora, já estou com 20 anos nas costas, estou saindo desde os 14, eu nunca fiz um exame (...)” (C3, $M, 22)$

"E quando eu voltei para noite [profissional do sexo], eu fiz o exame (...) e eu tive um susto, porque eu descobri que eu tinha sifilis." (C8, F, 32)

"Comecei a ser acompanhada pelo ginecologista e pedi para ele solicitar exames de sangue, mas ele não me fez todas as coletas, mas também eu não fui especifica, entendeu, porque eu tinha vergonha, e o meu médico era homem para piorar, [risos] então eu tinha muita vergonha. E isso assim, fez 10 anos. O ano passado que eu fiz o tratamento, foram 10 anos que eu tinha a doença e não sabia." (C6, F, 30)

"E, nessa época, eu trabalhava no mercado, eu trabalhava na parte da faxina, aí, como eu ia mudar de setor, então eu precisei fazer os exames, que era mexer com alimentos. ” (C7, F, 36)

Destacam-se relatos que evidenciaram a atitude de persistência dos pesquisados na busca de um atendimento de saúde resolutivo. Anteriormente, ou concomitantemente, ao atendimento no serviço público especializado, os pesquisados percorreram outros serviços (Unidade Básica de Saúde, Unidade de Pronto Atendimento, Clínicas Particulares, etc.), os quais nem sempre se mostraram efetivos. Por exemplo, a colaboradora C6F foi notificada da sífilis em um banco de sangue e não foi encaminhada para tratamento. Apesar disso, buscou o serviço especializado para realizar novo exame e esclarecer o resultado recebido. Parece importante ressaltar a necessidade da rede de cuidados para o enfrentamento da epidemia de sífilis. Assim, na complexidade da prevenção, do contágio e do cuidado às pessoas com sífilis, coexistem questões individuais e sociais, juntamente com as dimensões técnica, de gestão, política e pedagógica ${ }^{(24)}$.

No relato de C5F ficou destacada a importância do apoio da profissional de saúde no momento da revelação diagnóstica no serviço especializado, por meio de um tratamento atencioso e acolhedor, que contribuiu para o fortalecimento emocional, para a aceitação do diagnóstico e para a adesão ao tratamento ${ }^{(14,15)}$ :

"Ela [profissional de saúde] falou assim: "fica calma, vai dar tudo certo". Aí ela falou assim: "ai, você tem sifilis, mas a gente vai cuidar, a gente vai te ajudar", e quando ela falou "a gente vai te ajudar", eu senti um alívio dentro do meu coração. Foi tão gostoso. É tão gostoso quando você se sente protegida (...). E ai foi quando eu tive mais força ainda pra continuar de pé e fazer esse tratamento." (C5, F, 18)

No contexto do diagnóstico, reações emocionais foram relatadas pelos participantes do presente estudo, assim como também descritas em outros estudos ${ }^{(12-14)}$ : tristeza, vergonha, culpa, preocupação quanto à cura e transmissão ao bebê. Isto reforça a necessidade de haver mais investimento para equipe ampliada e multiprofissional no campo da saúde, por exemplo, e da atuação de psicólogos na equipe, especialmente quando questões subjetivas interferem na adesão ao tratamento, ou geram sofrimento das pessoas envolvidas.

Diante da constatação de que a sífilis tinha tratamento e cura, os participantes relataram lidar com a notícia de modo "normal", demonstrando aceitação do diagnóstico e motivação para enfrentar ao tratamento.

"Então, pra mim, foi uma coisa normal, porque a hora que a moça falou: "olha, você tem sifilis", eu falei "tenho?". Mas eu falei: "tem cura?", ela falou: "tem” (...) Não adianta, se acontece com a gente, você saber que você fez aquilo [sexo desprotegido], você querer culpar os outros, não é, ai você tem que assumir, de um jeito, sem violência, sem nada, conversando, dialogando, porque errar, todo mundo erra, não é?! Então, é uma coisa imprevista. (C1, M, 51)

Então, eu ouvi isso [diagnóstico e orientações], não assim feliz, mas de uma forma bem calma, tranquila, porque sabendo que ainda era início, primária, e que havia cura. Então, era só eu andar na linha certinho, que ia ter, entendeu, essa cura aí, e que deu certo." (C4, M, 29)

Já outros relataram mal-estar, sobretudo pela presença de um sentimento de vergonha ou culpa por entenderem a sífilis como uma consequência de seu próprio descuido nas relações sem preservativo, e de uma desvalorização pessoal. Inclusive, estar com uma IST foi expresso como "sentir-se sujo", o que talvez se relacione ao julgamento de seu próprio comportamento sexual como imoral ou incorreto:

"É lógico que, nossa, ai vinha assim, tipo... as lembranças de, poxa, olha o que você fez, olha a consequência. Eu estou 
sendo sincera pra você, eu orava muito, eu agradecia muito a Deus, porque não foram consequências maiores.” (C6, F, 30)

“Eu, que tive uma DST, com as duas [gonorreia, sifilis] que eu peguei, eu já me senti um lixo, já me senti uma pessoa suja, entendeu? Porque, quando você pega, você se vê naquele estágio "nossa, cara, peguei uma DST", uma doença, significa que eu não estou, não estou me valorizando, não estou me cuidando, estou levando uma vida qualquer.” $(C 3, M, 22)$

Os participantes do estudo em questão relataram impacto emocional diante do diagnóstico: sentimentos de desespero, "choque", tristeza e medo, os quais pareceram associados à ausência de uma percepção prévia da vulnerabilidade para IST. E. no caso da infecção pelo parceiro estável, houve manifestação de tristeza e raiva ${ }^{(14)}$, não só pela doença em si, mas também pela suspeita. ou constatação. de infidelidade. Foi relatado ainda o reconhecimento da vulnerabilidade ao Vírus da Imunodeficiência Humana Adquirida (HIV), considerado por muitos como fonte de maior preocupação por ser incurável ${ }^{(15)}$.

Percebeu-se, no relato de C5F, sentimentos de raiva e negação, típicos do processo de luto. Para aderir ao tratamento, foi necessário lidar com sentimento de indignação e culpa, assim como o apoio de pessoas próximas ${ }^{(14,15)}$. Já o participante cuja parceira estava gestante relatou ter ficado apavorado pelo risco da transmissão congênita:

"Eu fiquei muito nervosa também comigo mesma. (...) Eu não queria saber que estava acontecendo aquilo comigo. Eu não estava acreditando. (...) [depois diz para si mesma] "Você confiou, então agora você vai ter que arcar com as suas consequências, porque não adianta você pegar e falar' eu não vou fazer o tratamento', porque vai ser pior para você." $(C 5, F, 18)$

“Ai, meu chão abriu. Nossa, chorei tanto, que a gente não espera, não é, sei lá... Uma convivência com uma pessoa há tanto tempo e, de repente, que eu pensei comigo, eu falei "nossa, podia ser pior, podia ser uma Aids”, não é, aí ia acabar com a minha vida, porque é, eu ia ter que viver de tratamento, de remédio, não é?!'” (C7, F, 36)

"E nessa que constou que eu estava com sifilis, eu tinha certeza que não era dela, que era de mim. Então, automaticamente, já expandiu minha mente, já sabia que eu tinha passado para ela, e nessa, ela já estava grávida! Então, eu já fiquei apavorado, eu falei "e agora? O que é que eu vou fazer?" (C3, $M, 22)$

Em geral, a aceitação do diagnóstico foi acompanhada pela responsabilização na realização do tratamento. Não foram encontrados nos relatos do presente estudo as reações de indiferença, fatalismo ${ }^{(15,22)}$ e negação do acometimento pela sífilis, mesmo após o recebimento do diagnóstico ${ }^{(9)}$.

Ressalta-se a importância que tem a postura do profissional da saúde na ocasião de revelar o diagnóstico de uma doença, de acolher os sentimentos dele derivados, de informar e esclarecer os procedimentos de tratamento e de discutir atitudes preventivas futuras ${ }^{(5,8,9,10)}$. Logo, constata-se a relevância da formação e da educação permanente do profissional de saúde para o trabalho em sexualidade ${ }^{(6,10,24)}$.

\section{As informações sobre a sífilis}

Esta categoria reúne os relatos sobre os conhecimentos acerca da sífilis, antes e após o diagnóstico, além do modo de aquisição. Alguns colaboradores relataram desconhecimento sobre a sífilis antes de vivenciarem a doença. Houve comentários sobre o fato de haver pouco, ou nenhum, material informativo sobre sífilis e da falta de hábito em buscar informações, quando não há suspeita nem sintomas de alguma enfermidade.

"Só quem vai lá ao consultório que sabe o que que é a sifilis, porque na própria Unidade de Pronto Atendimento não tem um cartaz sobre a sifilis, tem muita gente que não conhece (...). Nunca tinha ouvido falar em sifilis, nunca. É porque, dificilmente... é que eu sou uma pessoa... dificilmente ia ao médico, e quando eu também, sabe... não fico lendo os cartazes, essas coisas." (C1, M, 51)

"Não, eu nunca soube dessa doença. Eu nem sabia que existia essa doença, porque eu não sou de ler muito as coisas, eu não sou muito ligada no mundo.” (C5, F, 18)

“Mas sobre a sifilis eu não sabia, vim saber depois que eu fiz tudo [tratamento].” (C8, F, 32)

Assim, segundo os relatos dos participantes, os conhecimentos prévios sobre a sífilis eram escassos, sendo que alguns desconheciam a doença e outros tinham apenas a noção de que era uma IST, corroborando outros estudos ${ }^{(12,13,16)}$. Outros afirmaram também que, anteriormente, só possuíam conhecimentos sobre o HIV, tendo percebido a necessidade de se atualizarem acerca das demais IST. E ainda houve uma percepção de que somente quem adquire a IST apresenta conhecimentos específicos sobre ela ${ }^{(19)}$.

"Que, até então, eu nem conhecia o que é sifilis, não é, assim... eu sabia que era uma doença, porque tinha um amigo meu que ele teve com umas feridas no corpo, essas coisa assim.” (C7 F, 36)

"Não [conhecia a sifilis] a fundo, assim... sabia que era uma doença sexualmente transmissível.” (C6, F, 30)

"A hora que pegou lá o exame e ela [dermatologista] falou "ah, você tem sifilis", eu falei "que é que é isso?", não é, brother, eu já tinha noção que era uma DST.” (C2, M, 22) 
"Quando a gente ouve falar de doença sexualmente transmissivel, a gente só conhece o HIV, entendeu? A pessoa só conhece que tem uma hepatite A, uma hepatite B, uma sifilis, quando, ou ela busca, ou ela acaba sendo transmitida, porque a doença, no geral, para todo mundo, só existe o HIV, ninguém tem esse conhecimento, ninguém sabe que existem outras DST." (C3, M, 22)

"Sim, eu já havia [ouvido sobre] na adolescência, mas como fazia muito tempo, geralmente hoje a gente está mais preocupado com Aids, não é? As outras doenças que não parecem nada, mas são perigosas também, a gente, às vezes, esquece. "Ah, que é isso aqui? Nada não!” Só está preocupado com Aids só." (C4, M, 29)

Os participantes relataram a educação em saúde ao receberem informações específicas nos atendimentos de revelação diagnóstica pelo profissional de saúde e durante o seguimento do tratamento: as fases da sífilis, o tratamento, o risco de reinfecção, de transmissão vertical e sobre a cicatriz sorológica e, de certa forma, essas informações direcionaram a ações favoráveis ao tratamento, condizente com outros estudos ${ }^{(9,10,14,16)}$.

"No começo, eu fiquei assim meio... assim não tão de cabeça quente, falei "mas será que tem cura?” Eu fiquei, ela [médica] falou "não, [nome do participante] tem cura, você vai tomar Benzetacil, você vai seguir a dieta [no sentido de abstinência sexual]." (C1, M, 51)

"Ela [médica] explicou primeiro para mim, entendeu, o que que é sifilis, mostrou para mim fotos, explicou para mim o que é estágio ainda primário e que havia ainda chances de cura, desde que eu também ajudasse, colaborasse. (...) Então, é melhor tratar já, agora que está primária, porque senão, depois complica." (C4, M, 29)

"Eu lembro que o médico [ginecologista do posto de saúde] pegou, falou assim "olha, deu uma alteração, e a sifilis ela só é detectada pelo exame de sangue”. (...) E o médico falou assim "olha, o seu namorado, ele vai ter que se tratar.” (C8, F, 32)

"Ela [médica] falou assim "ó [nome da participante], e você, como vocêfica, é, tem muitos parceiro, não é, então, sempre tem que tomar cuidado, usar camisinha, não deixa de usar”, ela sempre, ela explicou isso para mim.” $(C 7, F, 36)$

"Dai eu busquei informação, dai eu passei no médico, ele me explicou que se eu cuidasse o mais rápido possível não ia transmitir para o meu filho, que dependia... Era ela se cuidar o mais rápido possível que conseguisse.” $(C 3, M, 22)$

Alguns participantes relataram também terem buscado informações adicionais realizando leituras, sobretudo pela internet ${ }^{(14,15)}$. Na contemporaneidade, a internet tornou-se uma fonte corriqueira de busca de informações, inclusive sobre as IST. Contudo, esse modo de adquirir informações pode ser superficial e inadequado.

"Ai eu fui ler a respeito, e eu vi o que era." (C2, $M, 22)$

"Mas, assim, eu tirei a dúvida sobre a sifilis na internet, essas coisas, então eu vi muita coisa, que pode chegar até a morte." (C7 F, 36)

"Entrei na internet, eu estudei muito sobre doenças, não só sifilis, como infecções, como hepatite, como tudo, HIV também, então eu li bastante, sabe, então hoje eu posso falar que eu tenho um conhecimento básico.” (C3, M, 22)

"Eu fui atrás para saber, enfim, tudo. Mas aqui eu já tive uma boa base disso, aí lá fora eu fui buscar mais informação ainda. Que hoje tem, basta ir lá e buscar. O Google ensina tudo." (C4, M, 29)

Enfim, observa-se que após os participantes do presente estudo receberem as informações necessárias sobre a infecção, seu tratamento, as complicações da sua ausência e a possibilidade de reinfeção, é que relataram a tomada de decisão e atitudes favoráveis de adesão ao tratamento. Sabe-se que a mera informação não garante atitudes preventivas devido à existência de outros fatores de vulnerabilidade individuais, sociais e institucionais. Entretanto, foi por meio das informações obtidas, além da experiência da doença, que hoje influenciam os comportamentos dessas pessoas.

Portanto, é imprescindível promover a educação em saúde, que garanta o acesso às informações, acompanhado de reflexões, com estímulo para que atitudes de autocuidado sejam assumidas antes e/ou após a ocorrência de infecções ${ }^{(24)}$. A educação em saúde pelo processo participativo, democrático e dialógico, com a valorização dos saberes prévios populares e a análise crítica e reflexiva das realidades de vida e saúde das populações, visa a promoção da autonomia no autocuidado de indivíduos e coletividades ${ }^{(25)}$.

Assim, ressalta-se a relevância da promoção de políticas públicas que promovam a saúde sexual e os direitos reprodutivos para a população em geral, incluindo a Educação Sexual nas escolas. Promovam ainda campanhas midiáticas, elaboração e disponibilização de materiais educativos ${ }^{(9,10)}$, atividades em grupo nas Unidades Básicas de Saúde e nos espaços comunitários. Além da formação e da educação permanente das equipes de saúde, de acordo com as especificidades e as necessidades em seus locais de trabalho e da população atendida ${ }^{(24,25)}$.

Espera-se que os resultados contribuam para a promoção da saúde junto a população em geral e seus parceiros, propondo novos modelos assistenciais, que contemplem um olhar diferenciado em relação a saúde sexual e reprodutiva. Com uma visão na alteração do foco na doença para o foco na pessoa que vivencia a infecção. Assim sendo, pode-se possibilitar a compreensão dos desafios no enfrentamento da epidemia de sífilis adquirida por meio das perspectivas subjetivas e singulares das pessoas acometidas, visando ações efetivas de prevenção e, no caso de contágio, da adesão ao tratamento. 
As limitações deste estudo referem-se ao pequeno grupo de participantes, que restringe a análise a partir de singularidades, que não permitem generalizações dos dados. As configurações das vivências deles estão restritas e condicionadas às variáveis relacionadas aos dados de identificação, como também às características do centro de saúde especializado em testagem e aconselhamento em que realizaram o tratamento, assim como àquelas referentes à sua localidade, região do estado e país.

\section{CONSIDERAÇÕES FINAIS}

O estudo evidenciou que o contágio da doença ocorreu pela desinformação, confiança no parceiro e comportamentos sexuais de risco. O diagnóstico da doença, por vezes, ocorreu tardiamente, e geralmente há a manifestação de sintomas e, diante deles, há reações emocionais de espanto e culpa a si ou ao parceiro.

Também se apurou que os participantes tinham conhecimentos prévios insuficientes sobre a doença e as informações recebidas ocorreram nos atendimentos com os profissionais de saúde que os acolheram e orientaram, contribuindo para a aceitação do diagnóstico, a decisão e adesão ao tratamento.

Competiria a toda a equipe de saúde investir na educação em saúde, atuando de forma empática, sem julgamentos, reforçando e ensinando o uso de preservativo como única forma de prevenção das IST.

Diante disso, ressalta-se que o reconhecimento e valorização das subjetividades e dos significados atribuídos pelos usuários aos seus processos de saúde-doença são competências a serem desenvolvidas e aprimoradas na formação continuada de profissionais de saúde.

\section{AGRADECIMENTOS}

Autores agradecem à equipe e aos gestores pela possibilidade de realização da coleta de dados em campo e aos participantes do estudo por gentilmente compartilharem suas experiências.

\section{CONFLITOS DE INTERESSE}

Autores declaram a inexistência de conflitos de interesse.

Manuscrito sobre dados parciais da dissertação intitulada: Sexualidade e Sífilis adquirida: relatos de pessoas que realizaram o tratamento. Universidade Estadual Paulista "Julio de Mesquita Filho", Faculdade de Ciências e Letras (campus Araraquara). 2016. 132f.

\section{REFERÊNCIAS}

1. Ministério da Saúde (BR). Secretaria de Vigilância em Saúde. Boletim Epidemiológico. 2016;47(35):5-11.

2. Santos A, Marques E, Pagnin D, Queiroz V. A new challenge for public health: syphilis. Diversitates Int J. 2017;9(2):65-81.

3. Centers for Disease Control and Prevention. Division of STD Prevention, National Center for HIV/AIDS, Viral Hepatitis, STD, and TB Prevention. Syphilis. Atlanta; 2016. [acesso em 2017 Ago 20]; Disponível em: https://www.cdc.gov/std/ stats $15 /$ syphilis.htm

4. European Centre for Disease Prevention and Control . Syphilis infections on the rise in Europe. 2016 [acesso em 2017 Ago 20]: Disponível em: https://ecdc.europa.eu/en/newsevents/syphilis-infections-rise-europe

5. Ministério da Saúde (BR), Secretaria de Vigilância em Saúde, Departamento de DST, Aids e Hepatites Virais. Protocolo clinico e diretrizes terapêuticas para atenção integral as pessoas com infecções sexualmente transmissíveis. Brasília: Ministério da Saúde; 2015.

6. Lazarini FM, Barbosa DA. Educational intervention in Primary Care for the prevention of congenital syphilis. Rev Latinoam Enferm. 2017;25:e2845.

7. Garcés JP, Rubiano LC, Orobio Y, Castaño M, Benavides E, Cruz A. La educación del personal de salud:clave para la eliminación de la sífilis congénita en Colombia. Rev Bioméd. 2017;37(3):416-24.

8. Guanabara MAO, Leite-Araújo MA, Matsue RY, Barros VL, Oliveira FA. Acesso de gestantes às tecnologias para prevenção e controle da sífilis congênita em Fortaleza-Ceará, Brasil. Rev Salud Pública. 2017;19(1):73-8.

9. Rodrigues ARM, Silva MAM, Cavalcante AES, Goyanna NF. Practice of nurses in the monitoring of syphilis in primary care. J Nurs UFPE On line. 2016;10(4):1247-55. 
10. Vasconcelos MIO, Oliveira KMC, Magalhães AHR, Guimarães RX, Linhares MDSC, Queiroz MVO, et al. Sífilis na gestação: estratégias e desafios dos enfermeiros da atenção básica para o tratamento simultâneo do casal. Rev Bras Promoç Saúde. 2016;29(Supl):85-92.

11. Souza LGS, Meireles AA, Tavares KMC, Menandro MSC. Intervenções psicossociais para promoção da saúde do homem em Unidade de Saúde da Família. Psicol Ciênc Prof. 2015;35(3):932-45.

12. Cavalcante AES, Silva MAM, Rodrigues ARM, Mourão JJ Netto, Moreira ACA, Goyanna NF. Diagnóstico e tratamento da sífilis: uma investigação com mulheres assistidas na atenção básica em Sobral, Ceará. DST - J Bras Doenças Sex Transm. 2012; 24(4):239-45.

13. Lima VC, Mororó RM, Feijão DM, Frota MVV, Martins MA, Ribeiro SM, et al. Percepção de mães acerca da sífilis congênita em seu concepto. Espaço Saúde. 2016;17(2):118-25.

14. Silva VSTD. Os (Des) caminhos da sífilis congênita em Botucatu/São Paulo [dissertação]. Botucatu: Universidade Estadual Paulista Júlio de Mesquita Filho; 2016.

15. Barbosa RJ, Santos MHS, Vianna PVC. Sífilis congênita: mães de uma cidade paulista de grande porte relatam suas vivências e relação com a rede de saúde [trabalho completo]. In: XX Encontro Latino Americano de Iniciação Científica, XVI Encontro Latino Americano de Pós-Graduação e VI Encontro de Iniciação à Docência - Universidade do Vale do Paraíba; 2016 Out. 27-28; São José dos Campos; 2016.

16. Silva AM, Sousa J, Albuquerque S, Moreira CA, Martins MC. Sentimentos de gestantes com diagnóstico de sífilis. Enf Enferm UFPI. 2015;4(2):84-91.

17. Minayo MCS. O desafio do conhecimento: pesquisa qualitativa em saúde. 13 $13^{\mathrm{a}}$ ed. São Paulo: Hucitec; 2013.

18. Bardin L. Análise de conteúdo. Lisboa: Edições 70; 2011.

19. Barbosa JAG, Freitas MIF. Percepções de homens com transtornos mentais sobre risco e autocuidado face às infecções sexualmente transmissíveis. Saúde Soc. 2014;23(2):523-35.

20. Mauch SDN, Almeida AMO, Santos MFS. O significado da sífilis no universo masculino: um estudo em representações sociais. Tempus (Brasília). 2012;6(3):127-43.

21. Tittes J, Aichelburg MC, Antoniewicz L, Geusau A. Enhanced therapy for primary and secondary syphilis: a longitudinal retrospective analysis of cure rates and associated factors. Int J STD \& AIDS. 2013;24(9):703-11.

22. Plant A, Stahlman S, Javanbakht M, Cross J, Montoya JA, Bolan R, et al. Syphilis Experiences and Risk Perceptions Among Repeatedly Infected Men Who Have Sex with Men. Perspect Sex Reprod Health. 2015;47(4):181-6.

23. Almeida VCD, Donalisio MR, Cordeiro R. Factors associated with reinfection of syphilis in reference centers for sexually transmitted infections. Rev Saúde Pública. 2017;51:64;1-9.

24. Sortica AC. Rede de atenção à saúde, sífilis e educação em saúde, a intersecção necessária: um estudo de caso sobre sífilis em gestante e congênita no município de Esteio [dissertação]. Porto Alegre: Universidade Federal do Rio Grande Sul; 2017.

25. Falkenberg MB, Mendes TDPL, Moraes EPD, Souza EMD. Educação em saúde e educação na saúde: conceitos e implicações para a saúde coletiva. Ciênc Saúde Colet. 2014;19(3):847-52.

\section{Endereço para correspondência:}

Débora de Aro Navega

Av. Nações Unidas, 10-22

Bairro: Centro

CEP: 17010-130 - Bauru - SP - Brasil

E-mail: deboradearonavega@gmail.com 